\title{
Climate change vulnerability zoning for suburban districts of Ho Chi Minh City
}

\author{
Linh T. Vu ${ }^{1 *}$, Lam T. Vo ${ }^{2}$, Dung M. Ho ${ }^{3}$, \& Loi K. Nguyen ${ }^{4}$ \\ ${ }^{1}$ Institute for Environment and Resources, Vietnam National University Ho Chi Minh City, Vietnam \\ ${ }^{2}$ Department of Agriculture and Rural Development of Ho Chi Minh City, Ho Chi Minh City, Vietnam \\ ${ }^{3}$ The Institute for Computational Science and Technology, Ho Chi Minh City, Vietnam \\ ${ }^{4}$ Research Center for Climate Change, Nong Lam University, Ho Chi Minh City, Vietnam
}

\begin{abstract}
ARTICLE INFO
Research Paper

Received: October 02, 2018

Revised: December 16, 2018

Accepted: February 20, 2019

\section{Keywords}

Adaptation

Climate change

GIS

Ho Chi Minh City

Vulnerability zoning

${ }^{*}$ Corresponding author

Vu Thuy Linh

Email: vtlinh.uk@gmail.com
\end{abstract}

\section{ABSTRACT}

The study aimed to partition vulnerabilities caused by climate change in suburban districts of Ho Chi Minh City by integrating the use of AHP and GIS. The subjects used data collected from different departments, from surveys in the study area, and consulted with experts in the field of research to assess the weight of factors: Exposure, sensitivity and adaptability. After overlapping component maps, the results showed that the high vulnerability to climate change in five suburban districts of Ho Chi Minh City by 2025 was dominated by Binh Chanh, Nha Be and Hoc. Area of 35,865.57 ha (accounting for 22.84\%). The low and medium damage was concentrated in $\mathrm{Cu} \mathrm{Chi}$ and Can Gio (the respective area was $36,354.33$ ha, equivalent to $23.16 \%$ and 84.762 .27 ha, equivalent to $54 \%$ ). In addition, the study proposed solutions to increase adaptation and mitigation of the impacts of climate change on the lives of people in the affected area.

Cited as: Vu, L. T., Vo, L. T., Ho, D. M., \& Nguyen, L. K. (2019). Climate change vulnerability zoning for suburban districts of Ho Chi Minh City. The Journal of Agriculture and Development 18(5), 98-107. 


\title{
Phân vùng tổn thương do biến đổi khi hậu đến các huyện ngoại thành của Thành Phố Hồ Chí Minh
}

\author{
Vũ Thùy Linh ${ }^{1 *}$, Võ Thị Làm ${ }^{2}$, Hồ Minh Dũng ${ }^{3} \&$ Nguyễn Kim Lợi ${ }^{4}$ \\ ${ }^{1}$ Viện Môi Trường và Tài Nguyên, Đại Học Quốc Gia TP.HCM, TP. Hồ Chí Minh \\ ${ }^{2}$ Sở Nông Nghiệp và Phát Triển Nông Thôn TP.HCM, TP. Hồ Chí Minh \\ ${ }^{3}$ Viện Khoa Học Công Nghệ Tính Toán, TP. Hồ Chí Minh \\ ${ }^{4}$ Khoa Môi Trường và Tài Nguyên, Trường Đại Học Nông Lâm TP.HCM, TP. Hồ Chí Minh
}

\section{THÔNG TIN BÀI BÁO \\ Bài báo khoa học \\ Ngày nhận: 02/10/2018 \\ Ngày chỉnh sửa: $16 / 12 / 2018$ \\ Ngày chấp nhận: 20/02/2019}

\section{Từ khóa}

Biến đổi khí hậu

GIS

Phân vùng tổn thương

Thành phố Hồ Chí Minh

Thích ứng

*Tác giả liên hệ

Vũ Thùy Linh

Email: vtlinh.uk@gmail.com

\section{TÓM TẮT}

Nghiên cứu nhằm phân vùng tổn thương do biến đổi khí hậu tại các huyện ngoại thành của TP. Hồ Chí Minh bằng cách tích hợp sử dụng phương pháp AHP và GIS. Đề tài sử dụng các số liệu thu thập được từ các Sở ban ngành, từ điều tra khảo sát trên địa bàn nghiên cứu và tham vấn ý kiến của các chuyên gia trong lĩnh vực nghiên cứu nhằm đánh giá trọng số cho các yếu tố phơi nhiễm, mức độ nhạy cảm và khả năng thích ứng. Sau khi chồng lấp các bản đồ thành phần, kết quả đạt được cho thây vùng nguy cơ tổn thương cao do biến đổi khí hậu trong huyện ngoại thành của TP. Hồ Chí Minh vào năm 2025 chủ yếu là Bình Chánh, Nhà Bè và Hóc Môn với diện tích 35.865,57 ha (chiếm 22,84\%). Phần tổn thương thấp và trung bình tập trung ở $\mathrm{Củ} \mathrm{Chi} \mathrm{và} \mathrm{Cần} \mathrm{Giờ} \mathrm{(diện} \mathrm{tích} \mathrm{tương} \mathrm{ứng} \mathrm{là}$ $36.354,33$ ha tương đương $23,16 \%$ và $84.762,27$ ha tương đương $54 \%$ ). Bên cạnh đó, nghiên cứu còn đề xuất các giải pháp nhằm tăng khả năng thích ứng và giảm thiểu tác động của biến dổi khí hậu đến đời sống của người dân trong khu vực bị ảnh hưởng.

\section{1. Đặt Vấn Đề}

Kể từ thế kỷ 20 cho đến nay, biểu hiện của biến đổi khí hậu (BĐKH) đã diễn ra ngày càng rõ ràng hơn trên quy mô toàn cầu và ở từng khu vực. Thành phố Hồ Chí Minh (TP.HCM) được coi là một trong 10 thành phố hàng đầu trên thế giới có thể bị ảnh hưởng nghiêm trọng nhất bởi $\mathrm{BĐKH,} \mathrm{xếp} \mathrm{thứ} 5$ về số dân có thể bị ảnh hưởng của $\mathrm{BĐKH} \mathrm{vào} \mathrm{năm} 2070$ (Kreft \& Eckstein, 2013). Tính dễ bị tổn thương do $\mathrm{BĐKH}$ của TP.HCM là một mối lo ngại đặc biệt vì nó ảnh hưởng mạnh đến sự phát triển của Việt Nam khi thành phố này đóng góp tới $23 \%$ GDP và $20 \%$ tổng vốn đầu tư nước ngoài trực tiếp. Theo MONRE (2012 \& 2016), tùy theo từng kịch bản gia tăng mực nước biển mà mức độ và phạm vi ảnh hưởng đến TP.HCM cũng sẽ khác nhau. Theo đó, nó sẽ có khoảng từ 13,3\% - 36,2\% diện tích thành phố nguy cơ bị ngập tương ứng với sự gia tăng mực nước biển từ $0,5-2,0 \mathrm{~m}$. Hơn nữa, khoảng từ 4,5\% - 13,7\% dân số thành phố bị ảnh hưởng trực tiếp tương ứng với sự gia tăng mực nước biển này.

Rõ ràng là $\mathrm{BĐKH} \mathrm{sẽ} \mathrm{ảnh} \mathrm{hưởng} \mathrm{bất} \mathrm{lợi} \mathrm{đến}$ TP.HCM, đặc biệt là các huyện ngoại thành là nơi có tốc độ đô thị hóa còn thấp, còn nhiều hộ dân sống dựa vào ngành nông nghiệp và trình độ dân trí còn thấp. Vì vậy, để xây dựng bức tranh toàn cảnh tính dễ bị tổn thương do $\mathrm{BĐKH}$ cho các huyện ngoại thành của TP.HCM được thực hiện nhằm các mục tiêu xác định ảnh hưởng của BĐKH đến các huyện ngoại thành TP.HCM; Xây dựng bộ tiêu chí và đánh giá trọng số cho từng yếu tố phơi nhiễm, độ nhạy cảm và khả năng thích ứng; Thành lập bản đồ phân vùng tổn thương do 
BĐKH tại các huyện ngoại thành TP.HCM.

\section{Vật Liệu và Phương Pháp Nghiên Cứu}

Đề tài sử dụng thuật toán $\mathrm{AHP}$ và công cụ GIS để lập bản đồ phân vùng tổn thương do $\mathrm{BĐKH}$ theo phương pháp tổng quát của IPCC, 2007.

Tổn thương $\mathrm{BĐKH}=$ Mức độ phơi nhiễm trước hiểm họa + Tính nhạy cảm - Khả năng phục hồi: $\mathrm{Y}=\mathrm{E}+\mathrm{S}-\mathrm{AC}$.

Trong đó, Y là hệ số phân vùng tổn thương do $\mathrm{BĐKH;} \mathrm{E} \mathrm{là} \mathrm{chỉ} \mathrm{số} \mathrm{mức} \mathrm{độ} \mathrm{phơi} \mathrm{nhiễm} \mathrm{trước}$ hiểm họa (là mối đe dọa trực tiếp, mức độ thay đổi các yếu tố như mưa, nhiệt độ,...); S là chỉ số nhạy cảm. Mô tả các điều kiện môi trường của con người có thể làm trầm trọng thêm mức độ nguy hiểm, cải thiện những mối nguy hiểm hoặc gây ra một tác động nào đó hoặc các yếu tố kinh tế xã hội do tác nhân của con người gây ra; A là chỉ số khả năng phục hồi, thể hiện qua các giải pháp mà con người sử dụng trước, trong hoặc sau thiên tai để đối phó với các hậu quả bất lợi và là một hàm của các yếu tố xã hội. Với cách tiếp cận như trên, phương pháp luận nghiên cứu được thể hiện chi tiết như Hình 1.

\subsection{Phương pháp điều tra}

Tiến hành thu thập dữ liệu thứ cấp về điều kiện kinh tế - xã hội và nhận thức, kinh nghiệm của người dân về $\mathrm{BDKH}$ và tác động của $\mathrm{BDKH}$ đến người dân trong vùng nghiên cứu và sự hỗ trợ của chính quyền.

Số lượng mẫu điều tra: Xác định theo công thức của Yamane (1967): $\mathrm{n}=\mathrm{N} /\left(1+\mathrm{N} \times \mathrm{e}^{2}\right)$.

Trong đó, $\mathrm{n}$ là số lượng mẫu cần xác định cho nghiên cứu điều tra; $\mathrm{N}$ là tổng số dân TP.HCM năm 2014; e là mức độ chính xác mong muốn (1độ tin cậy) (chọn độ tin cậy là $92 \%$ ).

Dựa vào tỉ lệ dân số của từng huyện, tác giả sẽ lựa chọn đối tượng ngẫu nhiên với cỡ mẫu cần điều tra trên từng huyện cụ thể: Huyện Củ Chi có 40 phiếu và tập trung vào xã Tân Phú Trung vì xã này chuyên trồng rau an toàn; Huyện Hóc Môn có 41 phiếu; Huyện Bình Chánh với 55 phiếu tập trung vào xã Tân Nhựt là xã trồng lúa và cũng thường xuyên xảy ra ngập lụt; Huyện Cần Giờ với 8 phiếu tương đương 4,9\% tập trung tại xã Long Hòa; Huyện Nhà Bè với 13 phiếu tập trung tại xã Phước Hiệp, xã có mức độ ngập cao và hay xảy ra sạc lở.

\subsection{Phương pháp AHP}

Trên cơ sở mục tiêu đánh giá vùng tổn thương do $\mathrm{BĐKH}$ dựa trên $\mathrm{AHP}$, bước đầu tiên cần tiến hành đó là tổng hợp các yếu tố ảnh hưởng đến phân vùng tổn thương $\mathrm{BĐKH}$ trên khu vực nghiên cứu. Để có được thông tin đầy đủ, đúng đắn về vấn đề này, phương pháp lược khảo tài liệu và điều tra thực địa được sử dụng. Lược khảo tài liệu giúp nhà nghiên cứu tổng hợp bức tranh toàn cảnh về $\mathrm{BĐKH} \mathrm{trên} \mathrm{địa} \mathrm{bàn} \mathrm{nghiên} \mathrm{cứu} \mathrm{từ} \mathrm{quá}$ khứ đến hiện tại. Trong khi đó, khảo sát thực địa giúp nhà nghiên cứu hiểu rõ hơn về thực trạng tác động của BĐKH tại khu vực nghiên cứu cũng như đời sống người dân như thế nào, mối quan hệ giữa $\mathrm{BĐKH}$ với họ ra sao, những yếu tố tiềm tàng nào có thể tác động đến tính tổn thương trong thời gian sắp tới.

Từ kết quả lược khảo tài liệu và điều tra thực địa, một danh sách các yếu tố ảnh hưởng đến phân vùng tổn thương do $\mathrm{BĐKH}$ được xây dựng. Những yếu tố này có thể phân thành 4 nhóm: tự nhiên, kinh tế, xã hội, cơ sở hạ tầng.

Dựa trên danh sách các yếu tố ảnh hưởng đến phân vùng tổn thương do $\mathrm{BĐKH}$ đã thống kê, tiến hành lựa chọn ra những yếu tố ảnh hưởng lớn nhất. Sau đó, một cấu trúc thứ bậc được xây dựng để sắp xếp các yếu tố đã chọn theo từng cấp bậc khác nhau, tạo tiền đề cho quá trình so sánh cặp.

Sau khi đã thiết lập thứ bậc cho các tiêu chí, tiếp theo là cho điểm so sánh theo cặp giữa các tiêu chí. Công việc này đòi hỏi cần có sự tham vấn nhiều chuyên gia đến từ các trường đại học, viện nghiên cứu, cơ quan chính phủ và chính quyền địa phương đại diện cho các lĩnh vực khác nhau. Một bảng câu hỏi được chuẩn bị theo từng chủ đề: (1) Lựa chọn các yếu tố ảnh hưởng đến phân vùng tổn thương do $\mathrm{BDKH,} \mathrm{(2)} \mathrm{Đánh} \mathrm{giá} \mathrm{việc} \mathrm{lựa}$ chọn các yếu tố, (3) So sánh mức độ quan trọng giữa từng cặp yếu tố. Điểm số so sánh cặp cuối cùng cho các tiêu chí sẽ được tất cả các chuyên gia thảo luận và thống nhất.

Do giá trị điểm số trong ma trận so sánh cặp chỉ là định tính nên cần phải chuyển đổi chúng thành các giá trị định lượng và kiểm tra tính nhất quán của ma trận. Quá trình này được thực hiện thông qua AHP. Cuối cùng, nếu tỉ số nhất quán $(\mathrm{CR}) \leq 10 \%$, kết quả tính toán trọng số của từng yếu tố sẽ được công nhận. Ngược lại, sẽ cần thực hiện lại bước phân tích ý kiến chuyên gia.

Dựa trên trọng số tính toán, kết hợp với việc 


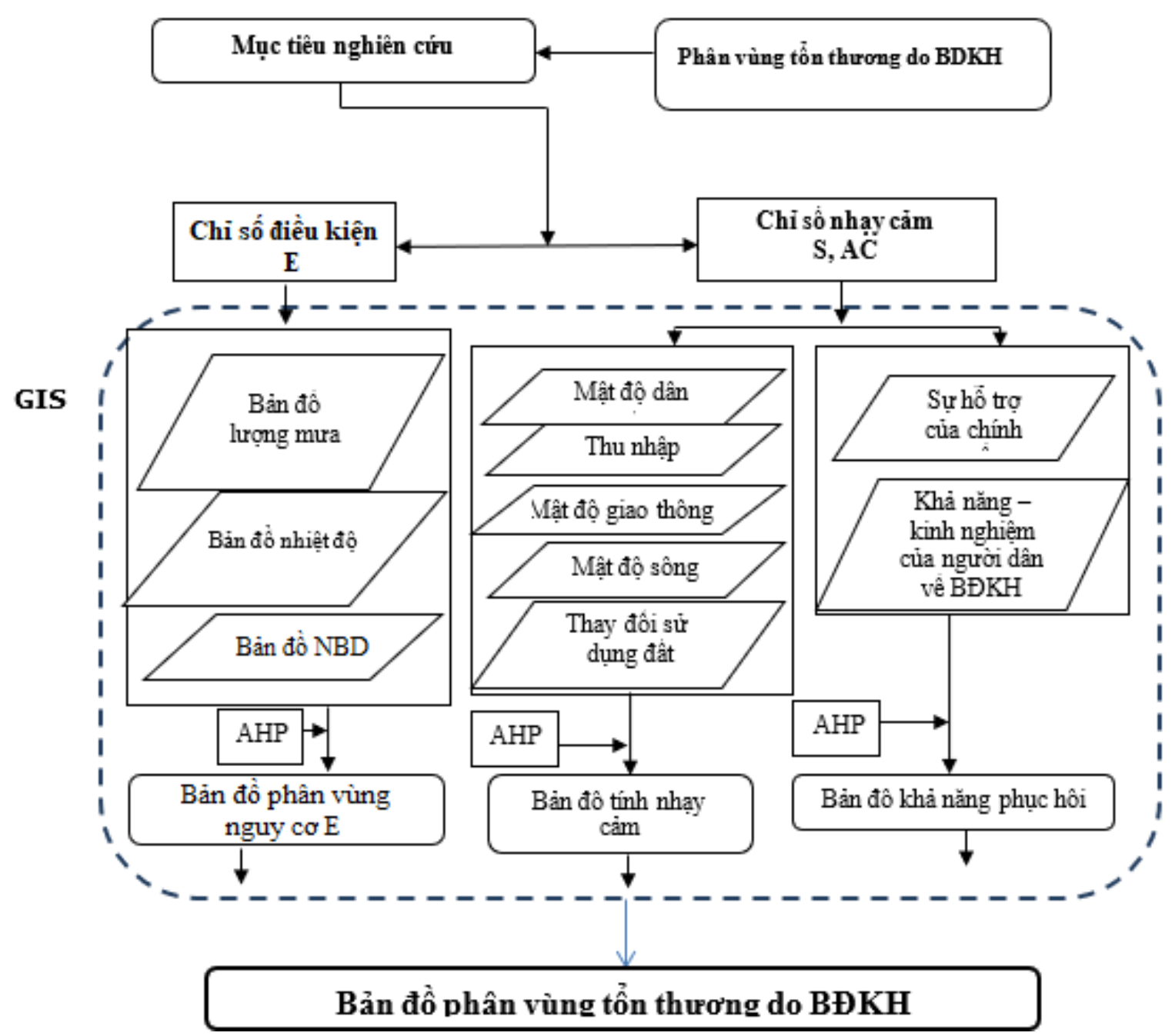

Hình 1. Sơ đồ phương pháp luận.

phân cấp, chuẩn hóa tổn thương cho từng tiêu chí, tiến hành chồng lớp thành lập bản đồ phân vùng tổn thương $\mathrm{BĐKH}$ cho toàn vùng nghiên cứu.

\subsection{Phương pháp GIS phân vùng tổn thương do BĐKH}

Xác định được trọng số các yếu tố nghiên cứu và xây dựng được các lớp thuộc tính cho các bản đồ lượng mưa, xâm nhập mặn, nước biển dâng, xu thế tăng nhiệt độ, kinh tế - xã hội sau đó tiến hành chồng lớp các bản đồ trên để xác định được điểm số vùng tổn thương $\mathrm{BDKH.} \mathrm{Điểm} \mathrm{số} \mathrm{này}$ thể hiện dưới phương trình tuyến tính sau:

$$
\mathrm{Y}=\Sigma_{\mathrm{i}=0}^{\mathrm{n}}\left(\mathrm{W}_{\mathrm{Ei}} \times \mathrm{X}_{\mathrm{Ei}}\right)+\Sigma_{\mathrm{j}=0}^{\mathrm{n}}\left(\mathrm{W}_{\mathrm{Sj}} \times \mathrm{X}_{\mathrm{Sj}}\right)-
$$

$\sum_{\mathrm{k}=0}^{\mathrm{n}}\left(\mathrm{W}_{\mathrm{Ak}} \times \mathrm{X}_{\mathrm{Ak}}\right)$.

Trong đó, Y là hệ số phân vùng nguy cơ dễ bị tổn thương do ảnh hưởng của $\mathrm{BDKH} ; \mathrm{W}_{\mathrm{Ei}}$ là trọng số các thành phần của $\mathrm{E} ; \mathrm{X}_{\mathrm{Ei}}$ là điểm các thành phần của $\mathrm{E} ; \mathrm{W}_{\mathrm{Sj}}$ là trọng số các thành phần của $\mathrm{S} ; \mathrm{X}_{\mathrm{Sj}}$ là điểm các thành phần của $\mathrm{S}$; $\mathrm{W}_{\mathrm{Ak}}$ là trọng số các thành phần của $\mathrm{A} ; \mathrm{X}_{\mathrm{Ak}}$ là điểm thành phần của $\mathrm{A}$. Thang đánh giá mức độ nguy cơ tai biến nói chung thường có ít nhất 2 cấp và nhiều nhất là 7 cấp (Nguyen, 2006). Số lượng các cấp phụ thuộc vào mục tiêu nghiên cứu, mức độ tài liệu có thể có, tỷ lệ nghiên cứu. Thang đánh giá mức độ nguy cơ thường được diễn tả theo mức dộ tăng lên như sau:

Thang 3 cấp: yếu (nhẹ, thấp), trung bình (vừa,...), cao (nặng, mạnh,...). 
Thang 5 cấp: rất yếu (rất nhẹ, rất thấp,...), yếu (nhẹ thấp, ...), trung bình (vừa,...), mạnh (nặng, cao,...), rất mạnh (rất nặng, rất cao,...).

Qua tìm hiểu, thống kê phân tích đánh giá các tài liệu có được và căn cứ vào sự phân hóa thực tế của mỗi yếu tố ảnh hưởng đến nguy cơ tổn thương do BĐKH, tác giả tiến hành phân chúng thành 4 cấp (Tổn thương thấp, Trung bình, Cao và Rất cao), tương ứng với thang điểm số từ 0 đến 3. Trên cơ sở đó khi phân cấp các tiêu chuẩn cũng được dựa theo thang phân của nguy cơ tổn thương do BĐKH.

\section{Kết Quả và Thảo Luận}

\subsection{Xác định trọng số tiêu chí của các yếu tố đánh giá tính dễ bị tổn thương}

Các câu hỏi được tác giả thiết kế thành bảng câu hỏi và phỏng vấn chuyên gia, các chuyên gia dùng kiến thức của mình để so sánh mức độ quan trọng của các yếu tố với nhau và cho điểm. Than điểm được thiết lập từ $0-9$, tại mỗi giá trị sẽ tương ứng với một thang điểm khác nhau. Sau khi có kết quả của 9 chuyên gia, nhóm tác giả sẽ tính toán chỉ số nhất quán cho từng chuyên gia trước khi tổng hợp lại thành một ma trận chung cho 9 chuyên gia.

\subsubsection{Trọng số đối với các tiêu chí của yếu tố độ phơi nhiễm $(\mathbf{E})$}

Trên cơ sở lược khảo tài liệu, các tiêu chí nhiệt độ, lượng mưa, nước biển dâng được sử dụng để thành lập bản đồ cho yếu tố phơi nhiễm do BĐKH. Với 9 bảng trả lời của chuyên gia, trọng số cho từng tiêu chí được trình bày trong Bảng 1.

\subsubsection{Trọng số đối với các tiêu chí của yếu tố độ} nhạy cảm (S)

Đối với yếu tố độ nhạy cảm thì các tiêu chí về Dân số, Thu nhập, Mật độ giao thông, Mật độ sông ngòi và Hiện trạng sử dụng đất được sử dụng đất. Khảo sát 9 chuyên gia, trọng số cho từng tiêu chí được trình bày trong Bảng 2 .

\subsubsection{Trọng số đối với các tiêu chí của các yếu tố khả năng thích ứng}

Các tiêu chí tượng trưng cho yếu tố khả năng phục hồi được tác giả lựa chọn là kinh nghiệp phòng chống các biểu hiện của $\mathrm{BDKH}$ với sự hỗ trợ của chính quyền địa phương (Bảng 3 ).

\subsection{Phân vùng tổn thương do $\mathrm{BĐKH}$ ở các huyê̂n ngoại thành TP.HCM}

\subsubsection{Xây dựng bản đồ phơi nhiễm}

Sau khi tính toán hệ số nguy cơ của khu vực nghiên cứu vào năm 2015 và 2025, so sánh kết quả của 2 năm thấy rằng độ phơi nhiễm của năm 2025 cao hơn so với năm 2015. Năm 2015 còn có vùng phơi nhiễm thấp nhưng qua năm 2025 chỉ có vùng phơi nhiễm trung bình, cao và rất cao (Hình 2). Kết quả năm 2025 so với năm 2015 thì diện tích vùng phơi nhiễm trung bình và rất cao tăng lên trong khi diện tích vùng phơi nhiễm thấp và cao giảm (Bảng 4). Phân cấp độ phơi nhiễm và diện tích từng vùng được thể hiện như sau: Cấp 1 là vùng có mức độ tổn thương thấp nhất; Cấp 2 là vùng tổn thương trung bình; Cấp 3 là mức tổn thương cao; Cấp 4 là mức tổn thương rất cao.

\subsubsection{Xây dựng bản đồ độ nhạy cảm}

Đối với năm 2015, vùng nhạy cảm thấp phân bố rải rác trên toàn khu vực nghiên cứu và tập trung chủ yếu ở Cần Giờ, vùng nhạy cảm trung bình phân bố ở cả khu vự nghiên cứu, vùng nhạy cảm cao tập trung chủ yếu ở Hóc Môn (Hình 3). Trong khi đó, năm 2025, vùng nhạy cảm trung bình nằm rải rác trên toàn khu vực nghiên cứu, nhiều nhất là Cần Giờ, vùng nhạy cảm cao trải dài cả khu vực nghiên cứu, vùng nhạy cảm rất cao chủ yếu là Hóc Môn và Nhà Bè. Phân cấp độ nhạy cảm và diện tích từng vùng được thể hiện như sau (Bảng 5): Cấp 1 là vùng có mức độ nhạy cảm thấp nhất; Cấp 2 là vùng nhạy cảm trung bình; Cấp 3 là mức nhạy cảm cao; Cấp 4 là mức nhạy cảm rất cao.

\subsubsection{Xây dựng bản đồ khả năng thích ứng}

Các yếu tố tượng trưng cho khả năng thích ứng được tác giả lựa chọn là kinh nghiệm phòng chống các biểu hiện của $\mathrm{BĐKH} \mathrm{với} \mathrm{sự} \mathrm{hỗ} \mathrm{trợ} \mathrm{của} \mathrm{chính}$ quyền địa phương. Các số liệu này được tác giả thực hiện thông qua điều tra phỏng vấn. Giả sử, khả năng thích ứng không thay đổi cho giai đoạn nghiên cứu 2025 (Hình 4).

Kết quả tính toán cho thấy giá trị hệ số khả năng phục hồi chạy từ 2 đến 3 , được phân thành 3 cấp như sau:

Cấp 1: Chủ yếu phân bố ở huyện Bình Chánh, 
Bảng 1. Trọng số các tiêu chí của yếu tố độ phơi nhiễm $(\mathrm{E})^{1}$

\begin{tabular}{lccc}
\hline Tiêu chí & Nhiệt độ $\left(\mathrm{E}_{1}\right)$ & Lượng mưa $\left(\mathrm{E}_{2}\right)$ & $\mathrm{NBD}\left(\mathrm{E}_{3}\right)$ \\
\hline Nhiệt độ $\left(\mathrm{E}_{1}\right)$ & 1 & 0,5 & 0,5 \\
Lượng mưa $\left(\mathrm{E}_{2}\right)$ & 2 & 1 & 0,5 \\
NBD $\left(\mathrm{E}_{3}\right)$ & 2 & 2 & 1 \\
Trọng số & 0,1103 & 0,3460 & 0,5438 \\
\hline $\begin{array}{l}{ }^{1} \text { Kết quả tính toán cho thấy } \\
\text { nhất quán. }\end{array}$
\end{tabular}

Bảng 2. Trọng số các yếu tố nhạy cảm¹

\begin{tabular}{lccccc}
\hline Yếu tố & Dân số & Thu nhập & $\begin{array}{c}\text { Mật độ } \\
\text { đường giao } \\
\text { thông }\end{array}$ & $\begin{array}{c}\text { Mật độ sông } \\
\text { ngòi }\end{array}$ & $\begin{array}{c}\text { Hiện trạng } \\
\text { sử dụng đất }\end{array}$ \\
\hline Dân số & 1 & 1 & 2 & 1 & 0,667 \\
Thu nhập & 1 & 1 & 2,200 & 2,250 & 2,500 \\
Mật độ đường giao thông & 0,500 & 0,455 & 1 & 1,125 & 0,333 \\
Mật độ sông ngòi & 1 & 0,444 & 0,889 & 1 & 1 \\
Hiện trạng sử dụng đất & 1,500 & 1 & 3 & 1 & 1 \\
Trọng số & 0,203 & 0,313 & 0,1 & 0,164 & 0,22 \\
\hline
\end{tabular}

${ }^{1}$ Kết quả tính toán cho thấy $\mathrm{CR}=0,058<0,1$. Như vậy, ma trận so sánh trên là nhất quán.
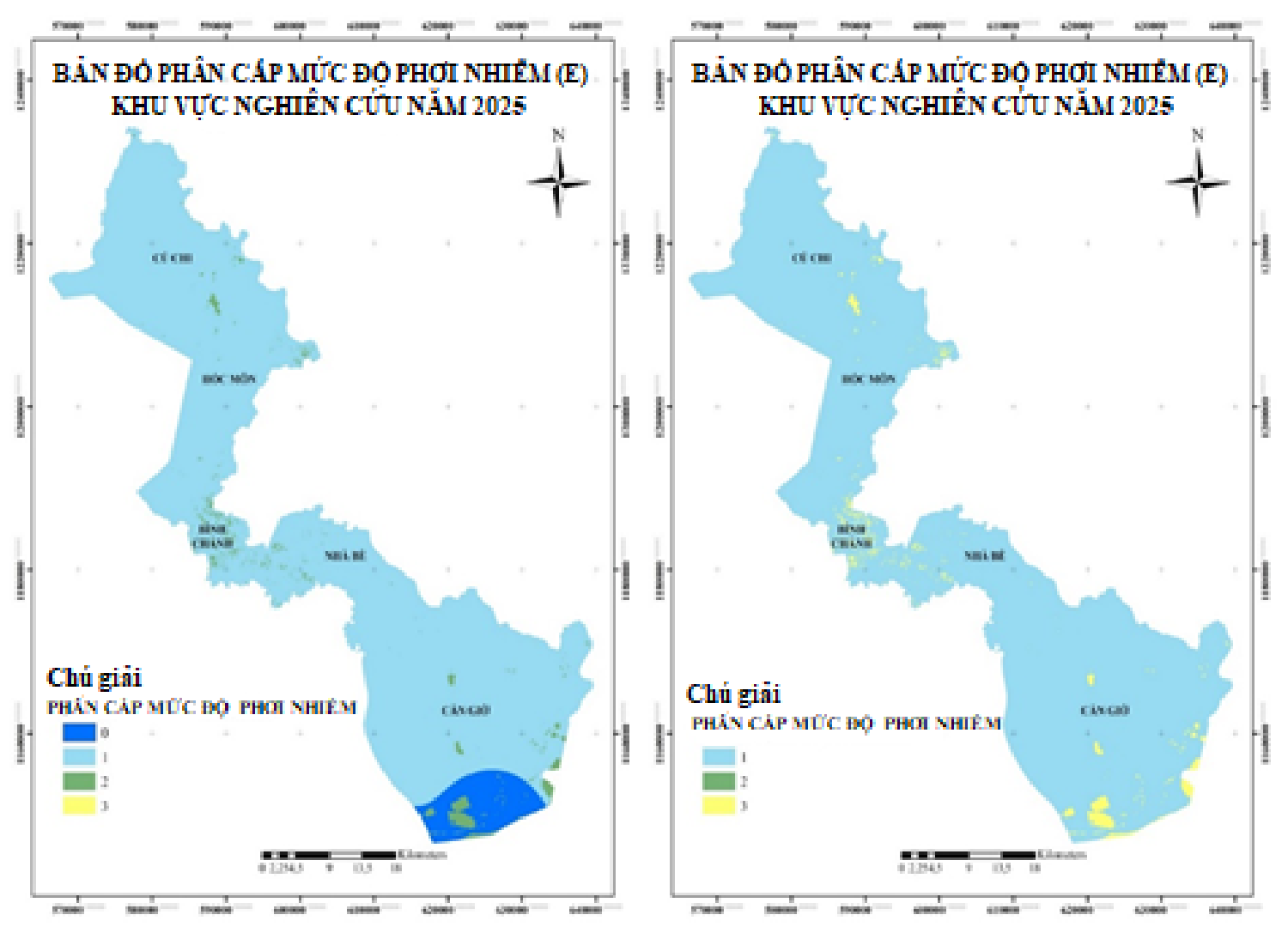

Hình 2. Bản đồ độ phơi nhiễm của khu vực nghiên cứu năm 2015 và 2025. 

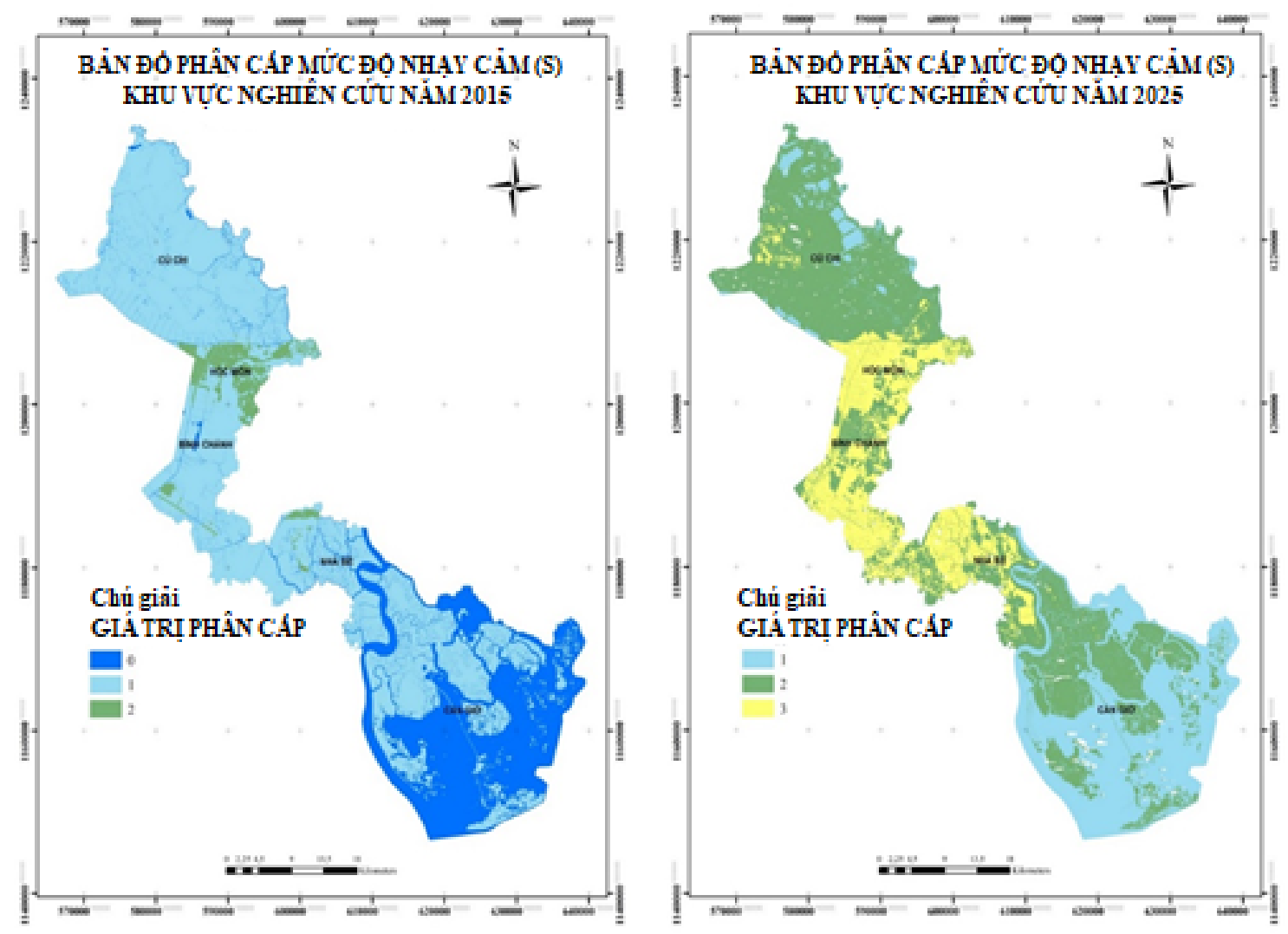

Hình 3. Bản đồ phân vùng nhạy cảm khu vực nghiên cứu năm 2015 và 2025 .

Bảng 3. Trọng số các tiêu chí yếu tố khả năng thích ứng ${ }^{1}$

\begin{tabular}{lcc}
\hline Tiêu chí & $\begin{array}{c}\text { Kinh nghiệm chống } \\
\text { BĐKH của người } \\
\text { dân }\end{array}$ & $\begin{array}{c}\text { Sự hỗ trợ chống } \\
\text { BĐKH của chính } \\
\text { quyền }\end{array}$ \\
\hline Kinh nghiệm chống BĐKH của người dân & $1 / 1$ & 0,33 \\
Sự hỗ trợ chống BĐKH của chính quyền & 3 & $1 / 1$ \\
Trọng số & 0,25 & 0,75 \\
\hline
\end{tabular}

${ }^{1} 1$ Kết quả tính toán cho thấy $\mathrm{CR}=0,002<0,1$. Như vậy, ma trận so sánh trên là nhất quán.

Nhà Bè, Cần Giờ. Cấp này chiếm diện tích 104.995,7 ha.

Cấp 2: Vùng có khả năng thích ứng trung bình có giá trị chạy từ 2 đến 2,25 . Phân bố chủ yếu huyện Hóc Môn. Cấp này có diện tích 10.908,36 ha.

Cấp 3: Vùng có khả năng thích ứng cao có giá trị chạy từ 2,25 đến 3 . Vùng có khả năng phục hồi cao và rất cao chủ yếu tập trung ở huyện Củ Chi. Diện tích tương ứng là 43.409,43 ha.
3.2.4. Xây dựng bản đồ tổn thương do $\mathrm{BĐKH}$ đến khu vực nghiên cứu

Bản đồ phân vùng tổn thương do BĐKH được xây dựng trên cơ sở chồng lấp ba bản đồ thành phần là yếu tố phơi nhiễm $(\mathrm{E})$, độ nhạy cảm $(\mathrm{S})$ và khả năng thích ứng $(\mathrm{A})$ theo công thức $\mathrm{Y}=$ $\mathrm{E}+\mathrm{S}-\mathrm{A}$.

Bản đồ tổng thương được phân theo 4 cấp: Cấp 1 là vùng có mức độ tổn thương thấp nhất; Cấp 2 là vùng tổn thương trung bình; Cấp 3 là mức tổn thương cao; Cấp 4 là mức tổn thương rất cao. 
Bảng 4. Diện tích phân cấp nguy cơ do biến đổi khí hậu tại các huyện ngoại thành

\begin{tabular}{cccccc}
\hline \multirow{2}{*}{ TT } & \multirow{2}{*}{ Phân cấp } & \multicolumn{2}{c}{ Năm 2015 } & \multicolumn{2}{c}{ Năm 2025 } \\
\cline { 3 - 6 } & & Diện tích (ha) & Tỷ lệ (\%) & Diện tích (ha) & Tỷ lệ (\%) \\
\hline 1 & Thấp & $8.578,08$ & 5,38 & 0,00 & 0,00 \\
2 & Trung bình & $14.7018,51$ & 92,28 & $155.596,59$ & 97,67 \\
3 & Cao & $3.716,28$ & 2,33 & 15,66 & 0,01 \\
4 & Rất cao & 0,63 & 0,01 & $3.701,25$ & 2,32 \\
\hline
\end{tabular}

Bảng 5. Diện tích phân cấp nhạy cảm do biến đổi khí hậu tại các huyện ngoại thành

\begin{tabular}{cccccc}
\hline \multirow{2}{*}{ TT } & \multirow{2}{*}{ Phân cấp } & \multicolumn{2}{c}{ Năm 2015 } & \multicolumn{2}{c}{ Năm 2025 } \\
\cline { 3 - 6 } & & Diện tích (ha) & Tỷ lệ (\%) & Diện tích (ha) & Tỷ lệ (\%) \\
\hline 1 & Thấp & $47.715,21$ & 29,95 & 0,00 & 0,00 \\
2 & Trung bình & $105.161,67$ & 66,01 & $47.824,11$ & 30,47 \\
3 & Cao & $6.436,62$ & 4,04 & $79.509,51$ & 50,65 \\
\hline
\end{tabular}

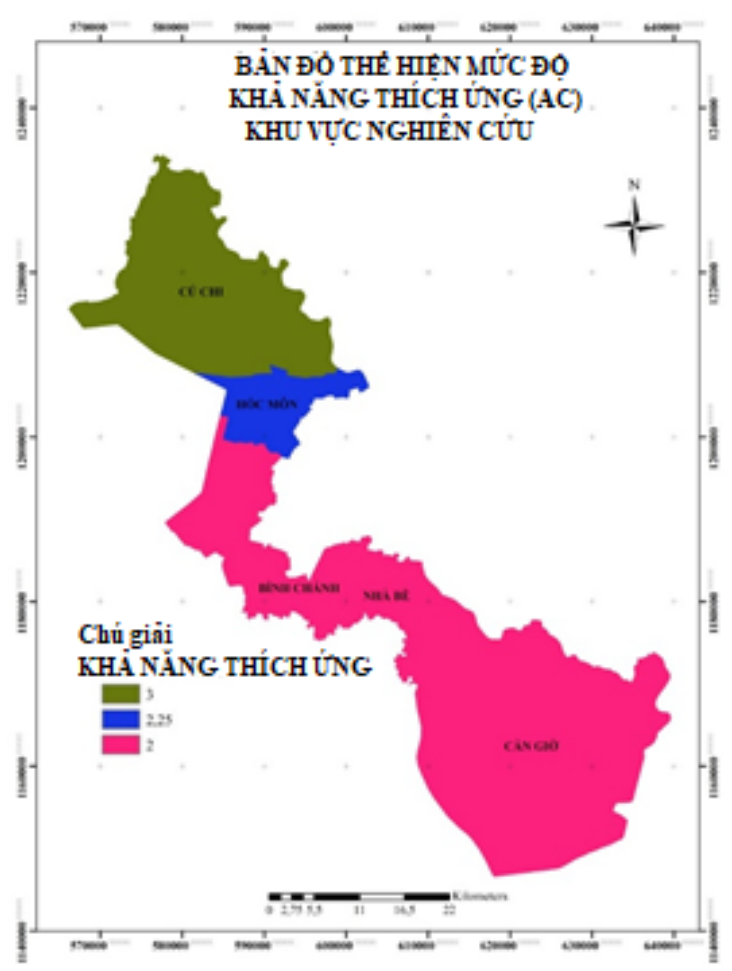

Hình 4. Bản đồ thích ứng khu vực nghiên cứu.

Năm 2015 mức tổn thương thấp và trung bình chiếm phần lớn diện tích, mức tổn thương cao và rất cao chỉ rải rác và tập trung chủ yếu ở khu vực Bình Chánh, Nhà Bè và Cần Giờ (Bảng 6). Năm 2025 mức độ tổn thương cao và rất cao chiếm tỷ lệ tương đối lớn. Chiếm hầu hết khu vực Bình Chánh, Nhà Bè, một phần Cần Giờ và có cả huyện Hóc Môn và Củ Chi.
So sánh 2 bản đồ năm 2015 và năm 2025 , mức độ tổn thương của năm 2025 cao hơn năm 2015, mức độ tổn thương thấp và trung bình giảm, tỷ lệ tổn thương cao và rât cao tăng nhanh (Hình $5)$.

3.3. Đề xuất các biện pháp thích ứng, giảm thiểu tác động của BĐKH đến khu vực nghiên cứu

Đây là các vùng ven của TP.HCM, là các huyện có sản xuất nông nghiệp, lâm nghiệp và nuôi trồng thủy sản. Trong tương lai, các huyện ngoại thành có hướng tới đô thị hóa nhưng vẫn đảm bảo một phần diện tích để sản xuất nông nghiệp, nông nghiệp cao. Các giải pháp đưa ra nhằm đảm bảo được tính đặc thù của khu vực:

Giải pháp phi công trình: Trong quá trình đô thị hóa, cần phải lồng ghép các tác động của BĐKH vào quy hoạch tổng thể hệ thống thoát nước của thành bố, quy hoạch tổng thể thoát nước,,.. để giảm hiện tượng ngập lụt tại các vùng có mức độ tổn thương cao; Nâng cao năng lực dự báo, phòng chống ngập lụt; Xây dựng và ban hành các quy định về cốt khống chế xây dựng, về hồ điều tiết, về hệ số mặt phủ tại các khu đô thị mới, quy chế về không gian dành cho nước... nhằm đảm bảo các yêu cầu thoát nước, ngăn chặn phát sinh điểm ngập mới được lồng ghép chặt chẽ trong lĩnh vực quy hoạch, xây dựng và quản lý đô thị; Tăng cường quản lý, giải quyết tình trạng lấn chiếm trái phép, xả rác trên các sông, kênh, rạch thoát nước trên địa bàn thành phố; tăng cường kiểm tra, xử lý tình trạng nhà dân lấn chiếm trái phép sông, kênh, rạch thoát nước và cải tạo, nạo vét thông thoáng toàn bộ kênh rạch thoát nước; 
Bảng 6. Diện tích phân vùng tổn thương do biến đổi khí hậu tại các huyện ngoại thành

\begin{tabular}{cccccc}
\hline \multirow{2}{*}{ TT } & \multirow{2}{*}{ Phân cấp } & \multicolumn{2}{c}{ Năm 2015 } & \multicolumn{2}{c}{ Năm 2025 } \\
\cline { 3 - 6 } & & Diện tích (ha) & Tỷ lệ (\%) & Diện tích (ha) & Tỹ lệ (\%) \\
\hline 1 & Thấp & $136.751,94$ & 85,84 & $36.354,33$ & 23,16 \\
2 & Trung bình & $21.160,89$ & 13,28 & $84.762,27$ & 54 \\
3 & Cao & $1.399,95$ & 0,87 & $34.602,21$ & 22,04 \\
4 & Rất cao & 0,72 & 0,01 & $1.260,36$ & 0,8 \\
\hline
\end{tabular}
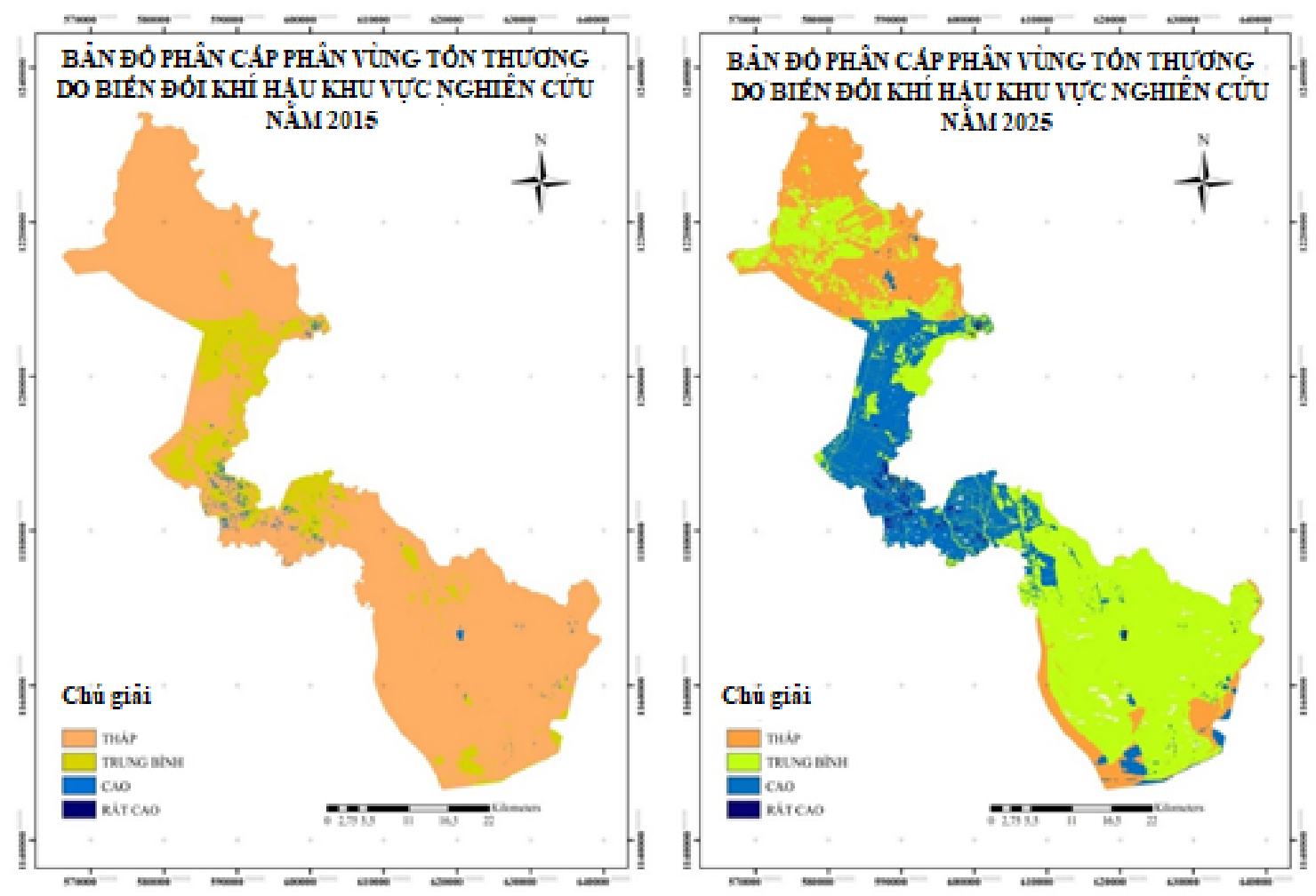

Hình 5. Bản đồ phân vùng tổn thương do BĐKH khu vực nghiên cứu năm 2015 và 2025 .

Tuyên truyền giáo dục người dân về tác động của $\mathrm{BĐKH}$ và hình thành ý thức chủ động ứng phó với $\mathrm{BĐKH}$; Thiết lập quy trình vận hành hồ chứa đa mục tiêu và thiết lập hệ thống cảnh báo sớm cũng như quy trình ứng phó; Bảo vệ rừng ngập mặn Cần Giờ, bảo tồn đa dạng sinh học, chú trọng bảo vệ và phát triển các hệ sinh thái, các giống, loài có sức chống chịu tốt với các thay đổi khí hậu; Bảo vệ và bảo tồn nguồn gien và các giống loài có khả năng bị tuyệt chủng do tác động của $\mathrm{BĐKH}$; Phát triển các loại cây trồng có khả năng chống chịu với điều kiện ngoại cảnh khắc nghiệt cũng như tăng cường các giống cây có thể chịu nhiệt, chịu hạn, chịu lụt ngắn ngày (do mưa úng) và các giống cây có biên độ sinh thái rộng. Đặc biệt, phát triển các loại cây hoa màu ngắn ngày; Cần phải xây dựng phương án phân ranh mặn - ngọt nhất là khu vực huyện Cần Giờ và tưới - tiêu tách rồi trong điều kiện $\mathrm{BDKH.}$ Từng bước chủ động tiêu nước bằng trạm bơm; Xây dựng phương án di dời các nhà ở ven sông, ven biển và vùng ngập trũng, nhằm đảm bảo tính mạng và tài sản nhân dân huyện Cần Giờ, Nhà Bè và Bình Chánh khi có bão, lụt lớn, sạc lở xảy ra.

Giải pháp công trình: Nâng cấp, hiện đại hóa các hệ thống công trình thủy lợi hiện hữu với việc 
đầu tư trang thiết bị thông tin, hệ thống quan trắc tự động, quản lý điều hành hệ thống một cách chủ động, khoa học, hiệu quả, đặc biệt các hệ thống cốn đầu mối; Xây dựng các hệ thống ngầm chống ngập thông minh để điều tiết nước khi có mưa to và triều lớn nhằm giảm thiểu ngập úng xảy ra; Đầu tư xây dựng, nâng cấp các hệ thống thủy lợi, đê biển, đê sông, đê cửa sông phòng chống lụt bão, nạo vét thông thoáng các kênh rạch hiện hữu đang bị bồi lắng nhằm phục vụ cấp nước, tiêu thoát nước bảo đảm an toàn cho dân sinh và vùng sản xuất, bảo vệ môi trường sinh thái; Áp dụng các giải pháp tưới tiên tiến, tiết kiệm nước cho các loại cây trồng cạn, cây công nghiệp, cây ăn quả có giá trị hàng hóa và kinh tế cao; Xây dựng phương án di dời các nhà ở ven sông, ven biển và vùng ngập trũng, nhằm đảm bảo tính mạng và tài sản nhân dân huyện Cần Giờ, Nhà Bè và Bình Chánh khi có bão; Xây dựng hệ thống kiểm soát, phòng chống dịch bệnh cây trồng và vật nuôi trong điều kiện $\mathrm{BĐKH}$.

\section{Kết Luận}

Với việc sử dụng phương pháp phân tích đa tiêu chí MCA cư thể là tiến trình phân tích thứ bậc $\mathrm{AHP}$, kết hợp với GIS để phân vùng tổn thương do BĐKH tại các huyện ngoại thành của TP.HCM, nghiên cứu đã phân vùng tổn thương do BĐKH, hầu như trên cả khu vực nghiên cứu đều tổn thương do BĐKH gây ra, khu vực tổn thương cao và rất cao hầu như tập trung ở Bình Chánh, Nhà Bè, Hóc Môn, Cần Giờ (diện tích là $35.862,57$ ha tương đương $22,84 \%$ ). Phần tổn thương thấp và trung bình tập trung ở $\mathrm{Củ}$ Chi và Cần Giờ (diện tích tương ứng là 36.354,33 ha tương đương $23,16 \%$ và $84.762,27$ ha tương đương $54 \%)$.

Dựa trên kết quả nghiên cứu, nhóm tác giả đã đề xuất các giải pháp về công trình và phi công trình nhằm tăng khả năng thích ứng và giảm thiểu tác động của $\mathrm{BĐKH}$ đến đời sống của người dân trong khu vực bị ảnh hưởng.

\section{Lời Cảm Ơn}

Nghiên cứu này là một phần kết quả Đề tài Ứng dụng GIS và mô hình hóa cho bản đồ đánh giá tính dễ bị tổn thương của biến đổi khí hậu ở TP.HCM và đề xuất giải pháp thích ứng giai đoạn đến năm 2050 theo hợp đồng số 29/2017/HĐSKHCN ngày $31 / 10 / 2017$ với Viện Khoa học và Công nghệ Tính Toán Thành phố Hồ Chí Minh. Nhóm nghiên cứu trân trọng cám ơn Sở Khoa học và Công nghệ và Viện Khoa học và Công nghệ Tính Toán Thành phố Hồ Chí Minh cấp kinh phí cho đề tài này.

\section{Tài Liệu Tham Khảo (References)}

IPCC (Intergovernmental Panel on Climate Change). (2007). Climate Change 2007: The AR4 Synthesis Report. Geneva, Switzerland: The Intergovernmental Panel on Climate Change.

Kreft, S., \& Eckstein, D. (2013). Global climate risk index 2014: Who suffers most from extreme weather events. Berlin, Germany: Germanwatch.

MONRE (Ministry of Natural Resources and Environment). (2012). Climate change scenarios, sea level rise for Vietnam. Ha Noi, Vietnam.

MONRE (Ministry of Natural Resources and Environment). (2016). Climate change scenarios, sea level rise for Vietnam. Ha Noi, Vietnam.

Nguyen T. Y. (2006). Research on zoning map of natural disasters in Vietnam - KC-08-01. (Unpublished research report). Institute of Geological Science.

Yamane, T. (1967). Statistics: An introductory analysis $\left(2^{\text {nd }}\right.$ ed.). New York, America: Harper and Row. 